\title{
Attitudes of Florida Pharmacists Toward Implementing a State Prescription Drug Monitoring Program for Controlled Substances
}

\author{
Jennifer A. Fass, PharmD, CPh, and Patrick C. Hardigan, PhD
}

\begin{abstract}
BACKGROUND: As of May 23, 2011, 35 states had an operational prescription drug monitoring program (PDMP), and 13 additional states, including Florida in 2009, had passed legislation to implement a PDMP. PDMPs, electronic databases that collect and track designated data on controlled substances and other commonly abused medications, are intended to serve as a tool for health care practitioners when prescribing and dispensing controlled substances to reduce drug abuse and diversion. In an analysis of 1,268 drug-caused deaths from January through June 2010 in Florida, the top 3 prescription drugs included the controlled substances oxycodone $(56 \%)$, alprazolam (35\%), and methadone (26\%), all of which would be subject to reporting in Florida's PDMP when implemented. Because pharmacists are the health care professionals most affected by PDMP reporting requirements, evaluating their attitudes about PDMP implementation is important.
\end{abstract}

OBJECTIVES: To assess Florida pharmacists' attitudes toward implementing a PDMP in the state.

METHODS: This was a cross-sectional study conducted in Florida between February 2010 and June 2010 prior to the implementation of the proposed PDMP. A random sample of 5,000 of approximately 26,000 pharmacists licensed in Florida was invited to participate in a voluntary and anonymous 10-question self-administered mail survey of which 4 survey items assessed pharmacists' attitudes towards implementing a PDMP in the state.

RESULTS: Of the 5,000 pharmacists contacted by mail, 911 (18.2\%) completed the survey, of whom 836 responded to the items assessing opinions about PDMPs and provided practice site information. A majority of pharmacists across all practice settings agreed or strongly agreed with the statements that a PDMP "should be implemented in Florida" (chain $84.0 \%$, hospital $74.2 \%$, independent $77.9 \%$, and other $71.1 \%$ ) and that a PDMP would decrease "the incidence of doctor shopping" if implemented (chain $80.8 \%$, hospital $67.2 \%$, independent $71.7 \%$, and other $63.3 \%$ ). A majority of pharmacists across all practice settings disagreed or strongly disagreed with the statements that they would be "discouraged to dispense controlled substances" by the PDMP (chain $61.4 \%$, hospital $50.0 \%$, independent $60.2 \%$, and other $63.8 \%$ ) and that PDMP implementation would be "an invasion of patients' privacy" (chain $80.3 \%$, hospital $67.7 \%$, independent $67.3 \%$, and other $69.3 \%$ ).

CONCLUSION: In a small-sample survey, a majority of Florida pharmacists across all practice settings were in favor of implementing a PDMP in Florida. This is the first study to examine Florida pharmacists' attitudes toward PDMP implementation, and the results should prompt future analyses of relevant outcomes, such as drug abuse, drug-related mortality, and doctor shopping.

J Manag Care Pharm. 2011;17(6):430-38

Copyright $\odot 2011$, Academy of Managed Care Pharmacy. All rights reserved.

\section{What is already known about this subject}

- As of May 2011, 35 states had an operational prescription drug monitoring program (PDMP), and 13 additional states, including Florida, had passed legislation to implement a PDMP. PDMP systems are classified as either reactive (information is sent based upon request) or proactive (data are regularly reviewed and reports are generated and sent to physicians, pharmacists, and regulatory agencies). PDMPs consist of 3 main components: collection of prescription information from physicians and pharmacists, data storage and processing, and regulations stipulating who is permitted to access the data.

- PDMPs may be effective in preventing and detecting prescription drug abuse and diversion; however, evidence is limited. The U.S. Government Accountability Office reported that implementation of Kentucky's PDMP reduced the average time necessary for regulatory agencies to conduct investigations of alleged doctor shoppers from 156 days to 16 days. Paulozzi and Stier found that the drug overdose death rate in Pennsylvania was 1.6 times that of New York in 2006; both states had PDMPs, but New York's PDMP had more funding and required tamper-proof prescription forms. However, Paulozzi et al. found that PDMPs in 19 states were not associated with lower rates of drug overdose, opioid mortality, or opioid consumption from 1999-2005.

- Only 2 published studies assessing pharmacists' attitudes towards PDMPs are available. The Kentucky All Schedule Prescription Electronic Reporting Program (KASPER) 2010 report found that more than $90 \%$ of participating pharmacists believed that KASPER was effective in preventing drug abuse and diversion and doctor shopping. Ulbrich et al. (2008) found in a survey of Ohio pharmacists that pharmacists not registered in Ohio's PDMP noted "time available to access the [PDMP] report" as the primary reason for nonenrollment, whereas pharmacists registered with the PDMP described "being able to assist with decreasing doctor shopping" as the top factor influencing their decision.

\section{What this study adds}

- After passage of a bill in 2009 to implement a PDMP in Florida and prior to its implementation, this survey conducted in a small sample of pharmacists in 2010 found that the majority of respondents across all practice settings agreed that the PDMP should be implemented (71\%-84\%) and that implementation of the PDMP would decrease the incidence of doctor shopping (63\%-81\%).

- A majority of respondents across all practice settings disagreed or strongly disagreed that the PDMP would discourage them from dispensing controlled substances (50\%-64\%) and that the PDMP would invade patients' privacy (67\%-80\%). 
A ccording to the 2009 National Prescription Drug Threat Assessment by the U.S. Department of Justice, prescription drug diversion and abuse result in medical costs of approximately $\$ 72.5$ billion per year in the United States. ${ }^{1}$ The 2009 National Survey on Drug Use and Health found that the rate of nonmedical use of psychotherapeutic prescription drugs among those aged 12 years or older increased from 2.5\% in 2008 to 2.8\% in 2009. ${ }^{2}$ Prescription drug abuse in Florida has become a major public health concern. In an analysis of 1,268 drug-caused deaths in Florida from January through June 2010, the top 3 prescription drugs included the controlled substances oxycodone (56\%), alprazolam (35\%), and methadone (26\%). ${ }^{3}$ Florida Governor Rick Scott reported in April 2011, based on a nonpeer-reviewed internal analysis of U.S. Drug Enforcement Agency (DEA) data, that 98 of the top 100 doctors dispensing oxycodone are located in Florida. ${ }^{4}$ Additionally, 126 million dosage units of oxycodone are dispensed through Florida pharmacies. ${ }^{4}$

Florida's Office of Drug Control was eliminated in the 2011 legislative session through Senate Bill 2104, which was signed by the governor on May 26, 2011. This bill moves the Statewide Drug Advisory Council into the Department of Health. ${ }^{5,6}$ The Office of Drug Control closure becomes effective July 1, 2011. ${ }^{7}$ The office had been dedicated to reducing prescription drug abuse throughout the state by leading a statewide task force, implementing new legislation, regulating pain clinics, and implementing drug take-back programs for the public to return expired, unused, and unwanted medications. ${ }^{8,9}$

A bill to establish a prescription drug monitoring program (PDMP) in Florida was passed during the 2009 legislative session and signed into law on June 18, 2009, after a 7-year battle. $^{10}$ The PDMP system is known as the ElectronicFlorida Online Reporting of Controlled Substances Evaluation Program (E-FORCSE) and, once implemented, will monitor controlled substances dispensed in schedules II-IV. ${ }^{11}$ The originally planned implementation date of December 1, 2010, was postponed due to funding issues and bids over the selection of the company that will run the program. The PDMP is expected to be operational by September 1, 2011.12 The E-FORCSE is being funded by a federal grant known as the Harold Rogers Prescription Drug Monitoring Program Grant $(\$ 400,000)$; an enhancement grant (used to make an improvement upon an existing PDMP, $\$ 400,000$ ); 2 private grants sponsored by the National Association of State Controlled Substances Authorities $(\$ 26,000)$; and donations by the Florida Prescription Drug Monitoring Foundation, Inc. ${ }^{11}$ Governor Rick Scott drafted a proposed bill for the 2011 legislature that would abolish the PDMP in Florida, and the bill was introduced by the House Health \& Human Services Committee. ${ }^{13}$ Proponents of the bill described various issues including questions about whether PDMPs are effective, privacy concerns, and lack of real-time access to data. ${ }^{14}$ However, the Florida Department of Health issued a final order on April 8, 2011, that begins implementation of the PDMP. ${ }^{15}$ Governor Scott testified to the U.S. House of Representatives on April 14, 2011, that the PDMP implementation is moving forward. ${ }^{4}$

\section{PDMPs: Rationale, Structure, and Evidence}

PDMPs are electronic databases that track and collect designated data on controlled substances and other commonly abused medications dispensed in each state. ${ }^{16,17}$ The goals of PDMPs are to support access to legitimate medical use of controlled substances, assist in identifying and preventing drug abuse and diversion, encourage the identification and treatment of individuals addicted to prescription drugs, evaluate state drug abuse trends, and serve as a public health education tool. ${ }^{16}$ Each PDMP is housed by a specified statewide regulatory, administrative, or law enforcement agency. The housing agency distributes data from the database to individuals who are authorized under state law to receive the information for professional purposes. Individuals who are usually identified as authorized requestors and users of PDMP data include licensed physicians/practitioners; pharmacists; designated federal, state, and local law enforcement; and representatives of professional or occupational licensing, certification or regulatory boards, commissions, or agencies. ${ }^{16}$

PDMPs typically consist of 3 main components: collection of prescription information from physicians and pharmacists, data storage and processing, and regulations stipulating who is permitted to access the data. Specific features of the PDMPs vary among the states, since each state government determines its own laws, regulations, and structure. ${ }^{16}$ PDMP systems are classified as either reactive (information is sent upon request) or proactive (data are regularly reviewed, and reports are generated and sent to physicians, pharmacists, and regulatory agencies). ${ }^{16,17}$

As of May 23, 2011, 35 states had an operational PDMP. ${ }^{18}$ Thirteen additional states, including Florida, have passed legislation to implement PDMPs, which are currently in the developmental stages. ${ }^{18}$ PDMPs vary in their stage of implementation and in the degree to which providers use the programs. For example, New Jersey adopted a law in 2008 to require a PDMP, and in April 2011, the state contracted with a private company to develop and implement the system. ${ }^{19}$ Washington's PDMP, which had been authorized in 2007, was suspended in 2008 due to budgetary constraints; however, the state received new federal funding in October 2010 to re-establish the program. ${ }^{20,21}$ Other states have more developed programs. For example, as of April 2011, 21\% of Maine pharmacists were registered as PDMP data requestors. ${ }^{22}$ This development is important because pharmacists are required to submit all transactions for schedule II-IV controlled substances; however, they are not required to access the database. ${ }^{22}$ States also differ in the drugs monitored ${ }^{16}$ For example, Pennsylvania's PDMP 
monitors only schedule II medications, whereas New York controls schedule II-V medications. ${ }^{16}$

Evidence suggests that PDMPs may serve as a tool to prevent and detect prescription drug abuse and diversion. ${ }^{23-32}$ However, the efficacy and utility of PDMPs throughout the United States have not been thoroughly analyzed. Curtis et al. measured the period prevalence of claims for opioid analgesics and controlledrelease oxycodone at the county level in 2000 , finding that a statewide schedule II PDMP, along with the proportions of the population aged 15 to 24 years and aged 65 years or older, were associated with opioid lower claim rates. ${ }^{25}$ Statewide PDMPs were also associated with lower use rates of controlled-release oxycodone. However, the study by Curtis et al. did not evaluate whether these associations resulted in a reduction in abuse and diversion or inadequate pain treatment. ${ }^{25}$ Paulozzi and Stier compared the death rates in New York and Pennsylvania in 2006. ${ }^{26}$ These states both have PDMPs; however, New York's PDMP had more funding and required tamper-proof prescription forms ${ }^{26}$ The drug overdose rate in Pennsylvania was found to be 1.6 times that of New York. ${ }^{26}$ Paulozzi et al. (2011) also published the first study evaluating the effect of PDMPs on opioid overdose mortality in 19 states..$^{33}$ This study found that PDMPs were not associated with lower rates of drug overdose, opioid mortality, or opioid consumption. ${ }^{33}$ PDMPs were associated with lower rates of schedule II drug use; however, the relationship was not significant, and PDMPs were associated with significantly higher use rates for hydrocodone, a schedule III drug. ${ }^{33}$ A limitation of the study by Paulozzi et al. was that $21 \%$ of PDMPs were only in their first few years of operation during the study period between 1999 and 2005; therefore, not all of the data may have been captured..$^{34}$ In a separate study, Paulozzi et al. (2009) examined data from the West Virginia Controlled Substances Monitoring Program to describe individuals dying from unintentional overdoses of methadone or other opioid analgesics and concluded that (a) most of these deaths were due to diversion and nonmedical use, and (b) providers, medical examiners, and coroners should review PDMP data routinely. ${ }^{35}$

The U.S. Government Accountability Office (GAO) examined the impact of PDMPs on illegal diversion of prescription drugs in Kentucky, Nevada, and Utah in 2002. ${ }^{27}$ The GAO found that implementation of Kentucky's PDMP reduced the average time necessary for regulatory agencies to conduct investigations of possible doctor shopping (i.e., obtaining multiple prescriptions for the same medication from different physicians) from 156 days to 16 days. The PDMPs were found to deter "doctor shopping," but diversion increased in the bordering states that did not implement a PDMP. ${ }^{27}$ Simeone and Holland (2006) found that states with PDMPs, especially those with proactive programs, had lower rates of supply of schedule II pain relievers and stimulant drugs compared with states that did not have PDMPs. ${ }^{31}$

\section{Reporting Requirements of Florida's Proposed PDMP}

The purpose of Florida's PDMP is to serve as a tool for health care practitioners when prescribing and dispensing controlled substances to reduce drug abuse and diversion throughout the state. The Florida statutes originally required that each controlled substance dispensed to an individual be reported to the Florida Department of Health within 15 days after the date the controlled substance was dispensed by a outpatient hospital pharmacy or community pharmacy. ${ }^{10}$ A new "Pill Mill" bill was passed on May 6, 2011, which requires data to be submitted within 7 days. ${ }^{36}$ Health care practitioners are exempt from reporting requirements in the following situations and practice settings: (a) when administering a controlled substance directly to a patient "if the amount of the controlled substance is adequate to treat the patient during that particular treatment session"; (b) when administering a controlled substance to a patient in "a hospital, nursing home, ambulatory surgical center, hospice, or intermediate care facility for the developmentally disabled"; (c) "when administering a controlled substance in the emergency room of a licensed hospital"; (d) "when administering or dispensing a controlled substance in the health care system of the Department of Corrections"; (e) "when administering or dispensing a controlled substance to a person under the age of 16"; and (f) "when dispensing a onetime, 72-hour emergency resupply of a controlled substance to a patient." 10 The reported information may be submitted via formats that include the Internet, disc, or regular mail. ${ }^{10}$

The PDMP in Florida will be in full compliance with the Health Insurance Portability and Accountability Act (HIPAA), including protected health information (PHI) and electronic PHI. ${ }^{10}$ As part of the provisions of HIPAA, states with an authorized PDMP have access to the patient's prescription history. Florida statute prohibits unauthorized access to and use of confidential patient information, and violations are a thirddegree felony. ${ }^{10}$ Florida-licensed pharmacists and physicians who have registered with the Department of Health will be permitted to access E-FORCSE. ${ }^{11}$ The following individuals or organizations may request access to patient-identifying information in E-FORCSE through the program manager: appropriate medical regulatory boards (e.g., Board of Pharmacy, Board of Medicine), the attorney general's Medicaid Fraud Unit, law enforcement, and patients verifying their own prescription histories. Additionally, the Florida Department of Health and Implementation and Oversight Task Force may request deidentified information for reporting purposes. ${ }^{11}$

The Florida Department of Health conducted a public hearing on November 9, 2010, to discuss proposed rules regarding the PDMP and hear public comments from the Florida Retail Federation and the Florida Academy of Family Physicians. ${ }^{37}$ The proposed rules, drafted by the Florida Board of Pharmacy, are based on the Florida controlled substance laws written for the PDMP. Health care practitioners may request to be alerted 
to "doctor shoppers" through a Patient Advisory Report (PAR), which will be updated weekly. ${ }^{37}$ However, PARs will be provided upon request only to physicians and pharmacists who have registered and been accepted. ${ }^{11}$

\section{Studies of Pharmacist Attitudes Regarding PDMPs}

Studies assessing pharmacists' attitudes towards PDMPs are limited. A study by Blumenschein et al. (2010) assessed the Kentucky All Schedule Prescription Electronic Reporting Program (KASPER) and found that more than $90 \%$ of participating pharmacists believed that KASPER was effective in preventing drug abuse/diversion and doctor shopping. ${ }^{32}$ Ulbrich et al. (2010) conducted an online survey of Ohio pharmacists to determine factors influencing registration for Ohio's PDMP, known as the Automated Rx Reporting System (OARRS) ${ }^{38} \mathrm{~A}$ total of 2,511 complete responses were recorded with 1,434 participants who indicated community pharmacy as their primary practice setting. Pharmacists not registered with OARRS noted "time available to access the OARRS report" as their primary reason not to enroll, whereas pharmacists registered with OARRS reported "being able to assist with decreasing doctor shopping" as their primary reason for PDMP enrollment. ${ }^{38}$

Because pharmacists are the health care professionals most affected by PDMP reporting requirements, evaluating their attitudes about PDMP implementation is important. The purpose of the present study was to assess the attitudes of Florida pharmacists toward PDMP implementation.

\section{Methods}

Five thousand pharmacists licensed in Florida as "active" status were randomly selected from 25,640 active Florida-licensed pharmacists listed in the Florida Licensee Data Center of the Department of Health. ${ }^{39}$ Pharmacists' mail addresses, names, and license information were used strictly for study purposes and were not linked back to any participants. No financial or other incentive was provided to respondents in this study. The state in which the pharmacist was currently practicing was not asked in the survey as part of the demographic information (see Limitations).

This was a voluntary and anonymous 10-question selfadministered survey accompanied by a cover letter with a description of PDMPs and a link to the text of Florida's PDMP bill (Appendix). An original survey was designed and pilottested with 10 pharmacists, and changes were made based on the feedback received. After receiving approval from the Institutional Review Board for Research with Human Subjects at Nova Southeastern University, we downloaded pharmacist information from the Licensee Data Center into a Microsoft Excel (Microsoft Corporation, Redmond, WA) spreadsheet in January 2010. Surveys were distributed through U.S. postal service mail in February 2010 followed by a reminder postcard mailed 1 week later to increase the response rate. Participants

\section{TABLE 1 Survey Participant Characteristics}

\begin{tabular}{l|rr}
\hline Years licensed as a pharmacist mean [SD] & 23 & {$[15]$} \\
\hline Characteristics & $\%^{\mathbf{a}}$ & $(\mathbf{n})$ \\
\hline Currently practicing & & \\
Yes & 92.6 & $(843)$ \\
No & 7.4 & $(67)$ \\
\hline Practice site & & \\
Chain & 44.7 & $(376)$ \\
Hospital & 23.7 & $(199)$ \\
Independent & 13.6 & $(114)$ \\
Other & 18.1 & $(152)$ \\
\hline PDMP knowledge & & \\
None & 21.4 & $(194)$ \\
Fair & 33.1 & $(300)$ \\
Good & 26.8 & $(243)$ \\
Very good & 13.3 & $(121)$ \\
Excellent & 5.4 & $(49)$ \\
\hline PDMP knowledge resources & & \\
Continuing education & 48.4 & $(345)$ \\
Pharmacy journal & 15.6 & $(111)$ \\
Newspaper & 10.4 & $(74)$ \\
Colleague & 8.3 & $(59)$ \\
Internet & 7.4 & $(53)$ \\
Television & 0.7 & $(5)$ \\
Other & 9.3 & $(66)$ \\
\hline
\end{tabular}

aPercentage of respondents to the item. Counts of respondents to the currently practicing, practice site, PDMP knowledge, and knowledge resources questions were 910, 841,907 , and 713 , respectively.

${ }^{b}$ Other = clinic pharmacy, academia, pharmaceutical industry, mail order pharmacy, nursing home/long-term care, home health/infusion.

$P D M P=$ prescription drug monitoring program; $S D=$ standard deviation.

were provided with a postage-paid envelope to ensure anonymity when returning the survey and to increase the response rate. Surveys were returned between February 2010 and June 2010 and tabulated in a Microsoft Excel spreadsheet.

The survey instrument included questions regarding practice status, such as the number of years licensed as a pharmacist and primary practice setting, and prior knowledge of PDMPs (Appendix). Practice setting was collapsed into the following 4 pharmacy sites: chain, hospital, independent, and other. The "other" category included clinic pharmacy, academia, pharmaceutical industry, mail order pharmacy, nursing home/ long-term care, home health/infusion, managed care, and government. Inpatient and outpatient hospital pharmacy practice settings were not differentiated (see Limitations). Likert-scale questions were used to assess prior knowledge (from $1=$ none to $5=$ excellent) and attitudes toward PDMPs (from $1=$ strongly disagree to $5=$ strongly agree). The last question enabled participants to provide comments and discuss issues not mentioned in the survey.

Descriptive statistics were calculated for all variables. Reliability of the 4 attitudinal questions was assessed using Cronbach's alpha. Questions 3 and 4 were reverse coded for the reliability analysis so that the attitudinal questions were ordered from less to more support. All data analyses were 
TABLE 2 Survey Responses by Practice Location

\begin{tabular}{|c|c|c|c|c|c|c|}
\hline Site & $\begin{array}{c}\text { Strongly Disagree } \\
\%(\mathrm{n})\end{array}$ & $\begin{array}{l}\text { Disagree } \\
\%(\mathrm{n})\end{array}$ & $\begin{array}{l}\text { Neither Agree nor } \\
\text { Disagree \% (n) }\end{array}$ & $\begin{array}{l}\text { Agree } \\
\%(n)\end{array}$ & $\begin{array}{c}\text { Strongly Agree } \\
\%(\mathbf{n})\end{array}$ & $\begin{array}{c}\text { Total } \\
\mathrm{N}\end{array}$ \\
\hline \multicolumn{7}{|c|}{ "A PMP should be implemented in Florida." $(\mathrm{N}=836)^{\mathrm{a}}$} \\
\hline Chain & $3.7 \quad(14)$ & (11) & $(35)$ & $35.4 \quad(133)$ & $48.7 \quad(183)$ & 376 \\
\hline Hospital & $5.1 \quad(10)$ & $2.5 \quad(5)$ & $18.2 \quad(36)$ & $39.4 \quad(78)$ & $34.8 \quad(69)$ & 198 \\
\hline Independent & 5.3 & (4) & 13.3 & 33.6 & 44.2 & 113 \\
\hline Otherb & $6.7 \quad(10)$ & 2.0 & $20.1 \quad(30)$ & 36.9 & 34.2 & 149 \\
\hline \multicolumn{7}{|c|}{ "The incidence of 'doctor shopping' will decrease if a PMP is implemented." $(\mathrm{N}=836)^{\mathrm{c}}$} \\
\hline Chain & $2.1 \quad(8)$ & $6.7 \quad(25)$ & $10.4 \quad(39)$ & $43.2 \quad(162)$ & $37.6(141)$ & 375 \\
\hline Hospital & 2.5 & $5.6 \quad(11)$ & 24.7 & 41.4 & 25.8 & 198 \\
\hline Independent & 5.3 & (9) & 15.0 & 37.2 & 34.5 & 113 \\
\hline Otherb & $6.7 \quad(10)$ & $8.0 \quad(12)$ & 22.0 & 35.3 & 28.0 & 150 \\
\hline \multicolumn{7}{|c|}{ "I would be discouraged to dispense controlled substances if a PMP is implemented." $(\mathrm{N}=836)^{\mathrm{d}}$} \\
\hline Chain & $25.3 \quad(95)$ & $36.2(136)$ & $26.6(100)$ & $(27)$ & (18) & 376 \\
\hline Hospital & $17.2 \quad(34)$ & $32.8 \quad(65)$ & $36.9 \quad(73)$ & 11.1 & 2.0 & 198 \\
\hline Independent & $30.1 \quad(34)$ & $30.1 \quad(34)$ & $22.1 \quad(25)$ & 10.6 & 7.1 & 113 \\
\hline Otherb & $22.1 \quad(33)$ & 41.6 & $(29)$ & 10.1 & (10) & 149 \\
\hline \multicolumn{7}{|c|}{ "Implementation of a PMP would be an invasion of patients' privacy." $(\mathrm{N}=836)^{\mathrm{e}}$} \\
\hline Chain & $39.2(147)$ & $41.1 \quad(154)$ & $(39)$ & $(22)$ & $(13)$ & 375 \\
\hline Hospital & $28.8 \quad(57)$ & $38.9 \quad(77)$ & 21.2 & $(16)$ & 3.0 & 198 \\
\hline Independent & $36.3 \quad(41)$ & 31.0 & (22) & (5) & (10) & 113 \\
\hline Otherb & 31.3 & 38.0 & $(28)$ & (12) & 4.0 & 150 \\
\hline \multicolumn{7}{|c|}{$\begin{array}{l}\text { aPearson chi-square with Yates' correction }=24.76, P=0.01 \text {. } \\
\text { 'Other }=\text { clinic pharmacy, academia, pharmaceutical industr } \\
\text { 'Pearson chi-square with Yates' correction }=37.28, P=0.01 \text {. } \\
\text { 'Pearson chi-square with Yates' correction }=28.66, P=0.01 \text {. } \\
\text { 'Pearson chi-square with Yates' correction }=28.65, P=0.01 \text {. } \\
\text { PMP = prescription drug monitoring program (PDMP). }\end{array}$} \\
\hline
\end{tabular}

conducted using STATA 11.0 (StataCorp LP, College Station, TX).

\section{Results}

Of the 25,640 Florida-licensed pharmacists as of February 2010, 5,000 randomly selected pharmacists were invited by mail to participate in the survey. Of these, 911 (18.2\%) completed the mail survey, of whom 836 answered the questions about attitudes toward the PDMP. The mean (SD) number of years a participant had been a licensed pharmacist was 23 (15), and a plurality (44.7\%) of respondents worked in a chain setting (Table 1). The reliability estimate (Cronbach's alpha) for the 4 -attitudinal questions was $78 \%$, indicating high internal consistency.

A majority of pharmacists across all practice settings agreed or strongly agreed with the statements that a PDMP "should be implemented in Florida" (chain 84.0\%, hospital 74.2\%, independent $77.9 \%$, and other $71.1 \%$ ) and that a PDMP would decrease "the incidence of doctor shopping" if implemented (chain $80.8 \%$, hospital $67.2 \%$, independent $71.7 \%$, and other 63.3\%) (Table 2). A majority of pharmacists across all practice settings disagreed or strongly disagreed with the statements that they would be "discouraged to dispense controlled sub- stances" by the PDMP (chain 61.4\%, hospital 50.0\%, independent $60.2 \%$, and other 63.8\%) and that PDMP implementation would be "an invasion of patients' privacy" (chain $80.3 \%$, hospital $67.7 \%$, independent $67.3 \%$, and other $69.3 \%$ ).

\section{Discussion}

Pharmacists in community practice are an important population to survey, since they are the health care professionals most affected by the PDMP implementation. The study results demonstrate that a majority of pharmacists across all practice settings are in favor of implementing a PDMP in Florida, believe that the PDMP will decrease the incidence of doctor shopping, would not be discouraged to dispense controlled substances if a PDMP is implemented, and do not believe that PDMP implementation would be an invasion of patients' privacy.

\section{Limitations}

Foremost among the study limitations is that the low response rate (18\%) must be considered when interpreting the survey results. We did not compare the demographic characteristics of the respondent sample with those of Florida pharmacists as a whole; thus, the degree of nonresponse bias is unknown. Second, pharmacists licensed in Florida but practicing in other 
states with PDMPs may have affected the results because these participants were more familiar with the program. Third, we did not differentiate inpatient from outpatient hospital pharmacy practice. It seems reasonable that inpatient hospital pharmacists as a group might be less engaged in the subject of a PDMP in Florida because inpatient hospital pharmacies are exempt from PDMP reporting. Fourth, limited background information was presented in the cover letter that was sent to pharmacists regarding the PDMP legislation. Although a link to the PDMP bill was provided, survey participants may not have accessed this information, which could have affected their responses.

\section{Conclusion}

As the gateway between the physician and patient, pharmacists are the health care professionals most affected by the PDMP implementation. The results demonstrate that a majority of pharmacists across all practice settings are in favor of implementing a PDMP in Florida. This is the first study to examine Florida pharmacists' attitudes toward PDMP implementation, and the results should prompt future analyses of relevant outcomes, such as rates of drug abuse, drug-related mortality, and doctor shopping.

\section{Authors}

JENNIFER A. FASS, PharmD, CPh, is a Clinical Assistant Professor; and PATRICK C. HARDIGAN, PhD, is Executive Director of Assessment, Evaluation, and Faculty Development, Nova Southeastern University, Fort Lauderdale, Florida.

AUTHOR CORRESPONDENCE: Jennifer Fass, PharmD, CPh, College of Pharmacy, Nova Southeastern University, 3200 S. University Dr., Ft. Lauderdale, FL 33328. Tel: 954.262.3169; E-mail: fass@nova.edu.

\section{REFERENCES}

1. U.S. Department of Justice, National Drug Intelligence Center. National prescription drug threat assessment 2009. Executive summary. Document 2009-L0487-001. April 2009. Available at: http://www.justice.gov/ndic/ pubs33/33775/execsum.htm\#Top. Accessed June 26, 2011.

2. U.S. Department of Health and Human Services, Substance Abuse and Mental Health Services Administration. Results from the 2009 National Survey on Drug Use and Health: volume I. Summary of national findings. NSDUH Series H-38A, HHS Publication No. SMA 10-4586Findings. September 2010. Available at: http://oas.samhsa.gov/ NSDUH/2k9NSDUH/2k9ResultsP.pdf. Accessed June 26, 2011.

3. Florida Department of Law Enforcement. Drugs identified in deceased persons by Florida medical examiners 2010 interim report. December 2010. Available at: http://www.fdle.state.fl.us/Content/getdoc/8a59bd00-c38d4bel-ac06-715a273b552e/MEC-2010-Interim-Report.aspx. Accessed June 26,2011

4. The Office of the 45th Governor of Florida Rick Scott. Governor Rick Scott's testimony of prescription drug diversion. April 14, 2011. Available at: http://www.flgov.com/2011/04/14/governor-rick-scott\%E2\%80\%99s-testimony-of-prescription-drug-diversion/. Accessed June 26, 2011.

5. Florida House of Representatives Office of Public Information. On track. June 21, 2011. Available at: http://www.myfloridahouse.gov/Sections/ Documents/loaddoc. aspx?DocumentType=Press\%20Release $\&$ FileName $=409$. Accessed June 26, 2011

6. Florida House of Representatives. Enrolled 2011 legislature. SB 2104, 2nd engrossed. Available at: http://www.myfloridahouse.gov/Sections/ Documents/loaddoc.aspx?FileName=_s2104er.DOCX\&DocumentType=Bill \&BillNumber=2104\&Session=2011. Accessed June 26, 2011

7. Florida House of Representatives. 2011 session summary. May 2011. Available at: http://www.myfloridahouse.gov/Sections/Documents/loaddoc. aspx?PublicationType $=$ Session $\&$ CommitteeId $=\&$ Session $=2011 \&$ Document Type $=$ End $\% 20$ of $\% 20$ Session $\% 20$ Summaries $\&$ FileName $=2011 \% 20$ End $\% 20$ Of\%20Session\%20Summary.pdf. Accessed June 26, 2011.

8. Florida Office of Drug Control. 2010 transition report. November 10, 2010. Available at: http://drugcontrol.flgov.com/pdfs/Transition_ReportNov\%205.pdf. Accessed June 26, 2011.

9. Florida Office of Drug Control. 2010 annual report. Available at: http:// drugcontrol.flgov.com/pdfs/2010_Annual_Report.pdf. Accessed June 26, 2011

10. Florida Statutes. Chapter 893: drug abuse prevention and control. 893.055 prescription drug monitoring program. Available at: http://www.leg. state.fl.us/statutes/index.cfm?App_mode=Display_Statute\&URL=Ch0893/ titl0893.htm\&StatuteYear $=2009 \&$ Title $=\% 2$ D\%3E2008\%2D\%3EChapter\%20 893. Accessed June 26, 2011

11. Florida Department of Health. Welcome to E-FORCSE: the state of Florida's prescription drug monitoring program. Available at: http://www. doh.state.fl.us/mqa/PDMP/home.html. Accessed June 26, 2011.

12. Florida Department of Health. Florida's prescription drug monitoring program. Fact sheet for healthcare practitioners. Available at: http:// www.doh.state.fl.us/mqa/PDMP/docs/Fact\%20Sheet-Health\%20Care\%20 Practitioners.pdf. Accessed June 26, 2011.

13. Florida House of Representatives. Proposed committee bill HHSC 11-04. Available at: http://www.myfloridahouse.gov/Sections/Documents/ loaddoc.aspx PublicationType $=$ Committees $\&$ CommitteeId $=2593 \& S$ ession=2011\&DocumentType=Proposed $\% 20$ Committee $\% 20$ Bills $\% 20$ (PCBs)\&FileName=PCB\%20HHSC\%2011-04.pdf. Accessed June 26, 2011.

14. Office of Public Information. OPI Pulse: repeal of the prescription drug monitoring program. March 8, 2011. Available at: http://www.myfloridahouse.gov/Sections/Documents/loaddoc.aspx?DocumentType=Press+Release $\&$ FileName=207. Accessed June 26, 2011.

\footnotetext{
The authors thank Kathleen Hagen, MM, Academic Research Evaluation Coordinator, Nova Southeastern University, for reviewing the manuscript.

This study received funding through an internal grant at the Nova submitted for presentation as a poster at the Midyear Clinical Meeting of Orleans, LA.

Concept and design were performed by Fass. Data were collected by Fass and analyzed by Hardigan with the assistance of Fass. The manuscript was written primarily by Fass and revised by Fass with the assistance of Hardigan

\section{ACKNOWLEDGEMENTS}


15. Office of the Attorney General of Florida. Attorney General Pam Bondi issues statement on prescription drug monitoring program. April 8, 2011. Available at: http://www.myfloridalegal.com/newsrel.nsf/newsreleases/32EE 4B8562546DB78525786C00725C91. Accessed June 26, 2011.

16. National Alliance for Model State Drug Laws (NAMSDL). Prescription drug monitoring programs: a brief overview. March 25, 2011. Available at: http://www.namsdl.org/documents/PMPsBriefOverview3-31-11.pdf . Accessed June 26, 2011

17. U.S. Department of Justice, Drug Enforcement Administration. Questions and answers: state prescription drug monitoring programs. June 2011. Available at: http://www.deadiversion.usdoj.gov/faq/rx_monitor.htm. Accessed June 26, 2011.

18. National Alliance for Model State Drug Laws. Status of state prescription drug monitoring programs. May 23, 2011. Available at: http://www.namsdl. org/documents/StatusofStates5-23-11.pdf. Accessed June 26, 2011.

19. National Association of Boards of Pharmacy. New Jersey to implement PMP. April 14, 2011. Available at: http://www.nabp.net/news/new-jersey-toimplement-pmp/. Accessed June 26, 2011.

20. National Association of Boards of Pharmacy. Federal funding will support relaunching of Washington PMP. October 1, 2010. Available at: http:// www.nabp.net/news/federal-funding-will-support-relaunching-of-washington-pmp/. Accessed June 26, 2011.

21. Washington State Department of Health. Prescription monitoring program. February 25, 2011. Available at: http://www.doh.wa.gov/hsqa/PMP/ default.htm. Accessed June 26, 2011.

22. State of Maine, Department of Health $\&$ Human Services, Office of Substance Abuse. Maine PMP update. April 28, 2011. Available at: http:// www.mnpa.us/handouts/Session\%2006c\%20-\%20PMP\%20Update.pdf. Accessed June 26, 2011

23. Fishbain D, Johnson S, Webster L, Greene L, Faysal J. Review of regulatory programs and new opioid technologies in chronic pain management: balancing the risk of medication abuse with medical need. J Manag Care Pharm. 2010;16(4):276-87. Available at: http://www.amcp.org/data/jmcp/276287.pdf.

24. Wang J, Christo PJ. The influence of prescription monitoring programs on chronic pain management. Pain Physician. 2009;12(3):507-15. Available at: http://www.painphysicianjournal.com/2009/may/2009;12;507-515.pdf. Accessed June 26, 2011.

25. Curtis LH, Stoddard J, Radeva JI, et al. Geographic variation in the prescription of schedule II opioid analgesics among outpatients in the United States. Health Serv Res. 2006; 41(3 Pt 1):837-55. Available at: http:// www.ncbi.nlm.nih.gov/pmc/articles/PMC1713206/pdf/hesr041-0837.pdf. Accessed June 26, 2011

26. Paulozzi LJ, Stier DD. Prescription drug laws, drug overdoses, and drug sales in New York and Pennsylvania. J Public Health Policy. 2010;31(4):422-32
27. U.S. General Accounting Office. Prescription drugs: state monitoring programs may help to reduce illegal diversion. March 4, 2004. Available at: http://www.gao.gov/new.items/d04524t.pdf. Accessed June 26, 2011.

28. Baehren DF, Marco CA, Droz DE, Sinha S, Callan EM, Akpunonu P. A statewide prescription monitoring program affects emergency department prescribing behaviors. Ann Emerg Med. 2010;56(1):19-23.

29. Katz N, Houle B, Fernandez KC, et al. Update on prescription monitoring in clinical practice: a survey study of prescription monitoring program administrators. Pain Med. 2008;9(5):587-94.

30. Katz N, Panas L, Kim M, et al. Usefulness of prescription monitoring programs for surveillance-analysis of schedule II opioid prescription data in Massachusetts, 1996-2006. Pharmacoepidemiol Drug Saf. 2010;19(2):11523

31. Simeone R, Holland L. An evaluation of prescription drug monitoring programs. September 1, 2006. Available at: http://www.simeoneassociates. com/simeone3.pdf. Accessed June 26, 2011

32. Blumenschein K, Fink JL, Freeman PR, Kirsh KL, Steinke DT, Talbert $\mathrm{J}$. Independent evaluation of the impact and effectiveness of the Kentucky All Schedule Prescription Electronic Reporting Program (KASPER). October 2010. Institute for Pharmaceutical Outcomes and Policy, University of Kentucky College of Pharmacy. Available at: http://www. chfs.ky.gov/NR/rdonlyres/24493B2E-B1Al-4399-89AD-1625953BAD43/0/ KASPEREvaluationFinalReport10152010.pdf. Accessed June 26, 2011

33. Paulozzi LJ, Kilbourne EM, Desai HA. Prescription drug monitoring programs and death rates from drug overdose. Pain Med. 2011;12(5):747-54.

34. Kerlikowske G, Jones CM, Labelle RM, Condon TP. Prescription drug monitoring programs-lack of effectiveness or a call to action? Pain Med. 2011;12(5):687-89.

35. Paulozzi LJ, Logan JE, Hall AJ, McKinstry E, Kaplan JA, Crosby AE. A comparison of drug overdose deaths involving methadone and other opioid analgesics in West Virginia. Addiction. 2009;104(9):1541-48.

36. Office of the Attorney General of Florida. Attorney General Bondi praises legislature for passing "pill mill" bill. May 6, 2011. Available at: http://www.myfloridalegal.com/newsrel.nsf/newsreleases/ A0B437B25C54419985257888007B09A4. Accessed June 26, 2011.

37. Florida Department of Health. Prescription drug monitoring program. Rule hearing: public agenda materials. November 9, 2010. Available at: http://www.eforcse.com/docs/Public_Book_Rule_Hearing_11-9-10.pdf. Accessed June 26, 2011.

38. Ulbrich TR, Dula CA, Green CG, Porter K, Bennett MS. Factors influencing community pharmacists' enrollment in a state prescription monitoring program. J Am Pharm Assoc (2003). 2010;50(5):588-94.

39. Florida Department of Health. Licensee data center. September 2005. Available at: https://ww2.doh.state.fl.us/downloadnet/Licensure.aspx. Accessed June 26, 2011. 


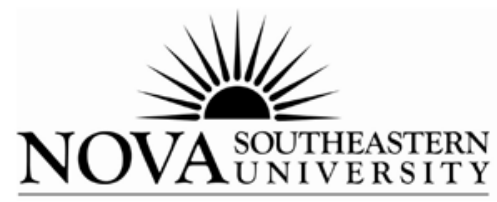

Dear Pharmacist,

I am a pharmacist affiliated with Nova Southeastern University. Your name has been randomly selected from the Florida Department of Health Licensee Data Center to participate in a voluntary and anonymous survey regarding your attitudes towards implementing a prescription monitoring program (PMP) in Florida. According to the Florida Medical Examiners Report, approximately 6 people died each day in Florida in 2008 with at least one prescription drug considered to be the cause of death. Florida became the 39th state to enact legislation to establish a PMP to monitor controlled substances on June 18, 2009 The purpose of this survey is to assess pharmacists' attitudes towards PMPs and their utility in Florida. Please note that this survey is not affiliated with the Florida Board of Pharmacy. Participation is voluntary and anonymous, and there are no negative consequences for choosing not to complete the survey. Please return your survey in the enclosed postage paid envelope. Thank you for your time, and please feel free to contact me with further questions.

Please access the following link if you would like to review Florida's PMP bill http://www.flsenate.gov/data/session/2009/Senate/bills/billtext/pdf/s0462er.pdf.

Sincerely,

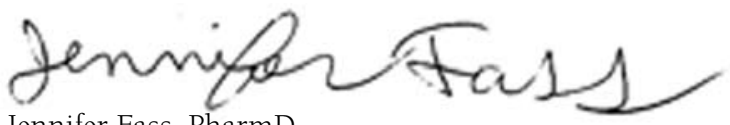

Jennifer Fass, PharmD

Clinical Assistant Professor

Nova Southeastern University

Department of Pharmacy Practice

954-262-3169

fass@nova.edu 
APPENDIX Survey Cover Letter and Questionnaire (continued)

Prescription Monitoring Program (PMP) Survey

Instructions: Please answer the questions to the best of your ability and return in the enclosed postage paid return envelope.

Please note that this survey is voluntary and anonymous.

1. How many years have you been licensed as a pharmacist?

(Please write the number of years)

2. Are you currently practicing as a pharmacist? (Please check the item of your answer)

Yes (Please continue to question 3)

No (Please skip to question 4)

3. Which is your PRIMARY area of practice? (Please check only one item of your answer)

\begin{tabular}{lll}
- & Pharmaceutical Industry \\
Independent Community Pharmacy & & Mail Order Pharmacy \\
Chain Pharmacy & - Nursing Home/Long Term Care \\
Clinic Pharmacy & - & Home Health/Infusion \\
Hospital Pharmacy & - Other (Please describe) \\
\hline
\end{tabular}

4. How would you rate your knowledge of PMPs prior to receiving this survey?

(Please circle the number that best represents your knowledge)

$\begin{array}{ccccc}1 & 2 & 3 & 4 & 5 \\ \text { None } & \text { Fair } & \text { Good } & \text { Very Good } & \text { Excellent }\end{array}$

5. If you rated your knowledge of PMPs as Fair, Good, Very Good, or Excellent, which source(s) provided you with information?

(Please check all answers that apply, and skip to question 6 if you rated your knowledge of PMPs as None)

$\begin{array}{ll}- \text { Continuing Education } & - \text { Internet } \\ \text { Newspaper } & - \text { Television } \\ \text { Pharmacy Journal } & - \text { Colleague } \\ & - \text { Other (Please describe) }\end{array}$

Please circle the number that best represents your opinion of PMPs for questions 6-9

$\begin{array}{ccccc}\begin{array}{c}\text { Strongly } \\ \text { Disagree }\end{array} & \text { Disagree } & \begin{array}{c}\text { Neither Agree } \\ \text { Nor Disagree }\end{array} & \text { Agree } & \begin{array}{c}\text { Strongly } \\ \text { Agree }\end{array} \\ 1 & 2 & 3 & 4 & 5 \\ 1 & 2 & 3 & 4 & 5 \\ 1 & 2 & 3 & 4 & 5 \\ 1 & 2 & 3 & 4 & 5\end{array}$

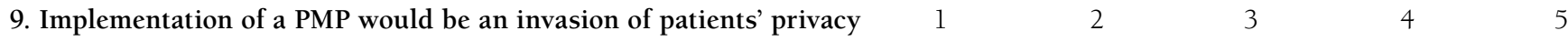

10. Please provide any additional items you would like to discuss that were not mentioned in the survey:

\footnotetext{
*This survey is not affiliated with the Florida Board of Pharmacy

Please return your completed survey in the postage paid envelope provided

Thank you for your participation!
} 